\title{
Supplementary Table:
}

Table S1. Contents of the secondary structural components and aggregates presented in these PPI samples

\begin{tabular}{ccccccc}
\hline Sample & $\beta$-Sheet (\%) & Random coil & $\alpha$-Helix $(\%)$ & $\beta$-Turn (\%) & Anti-parallel & Aggregates \\
& & $(\%)$ & & $\beta$-sheet $(\%)$ & $(\mathrm{A})(\%)$ \\
\hline EPPI-0h & $34.15 \pm 0.03^{\mathrm{A}}$ & $14.42 \pm 0.02^{\mathrm{B}}$ & $9.90 \pm 0.04^{\mathrm{C}}$ & $22.39 \pm 0.03^{\mathrm{C}}$ & $19.12 \pm 0.02^{\mathrm{A}}$ & $34.59 \pm 0.02^{\mathrm{A}}$ \\
EPPI-12h & $28.03 \pm 0.02^{\mathrm{B}}$ & $10.65 \pm 0.01^{\mathrm{C}}$ & $11.47 \pm 0.03^{\mathrm{A}}$ & $24.13 \pm 0.04^{\mathrm{B}}$ & $11.66 \pm 0.02^{\mathrm{C}}$ & $32.47 \pm 0.01^{\mathrm{C}}$ \\
EPPI-24h & $23.95 \pm 0.02^{\mathrm{C}}$ & $18.13 \pm 0.05^{\mathrm{A}}$ & $11.02 \pm 0.05^{\mathrm{B}}$ & $24.58 \pm 0.05^{\mathrm{A}}$ & $12.65 \pm 0.03^{\mathrm{B}}$ & $33.62 \pm 0.03^{\mathrm{B}}$ \\
\hline
\end{tabular}

Data was expressed as "mean \pm standard deviation". Different letters: A, B, C within the same column indicate statistically significant differences at $p<0.05$. 


\section{Supplementary Figures:}

Figure. S1. Processing chart of pea protein isolate from Shandong Liuliushun Foods Co., Ltd.

Figure. S2. Appearance of pea protein isolate dispersions (EPPI-0h, EPPI-6h, EPPI12h, EPPI-24h) after standing for $1 \mathrm{~min}, 30 \mathrm{~min}, 1 \mathrm{~h}$ and $2 \mathrm{~h}$.

Figure. S3. Particle size distribution as determined by light scattering of untreated and glutaminase-treated pea protein isolate (EPPI-0h, EPPI-12h and EPPI-24h) in deionized water at $25^{\circ} \mathrm{C}$. 
Figure S1

\section{SHANDONG LIULIUSHUN FOODS C0. , LTD. PEA PROTEIN ISOLATE PROCESSING CHART}

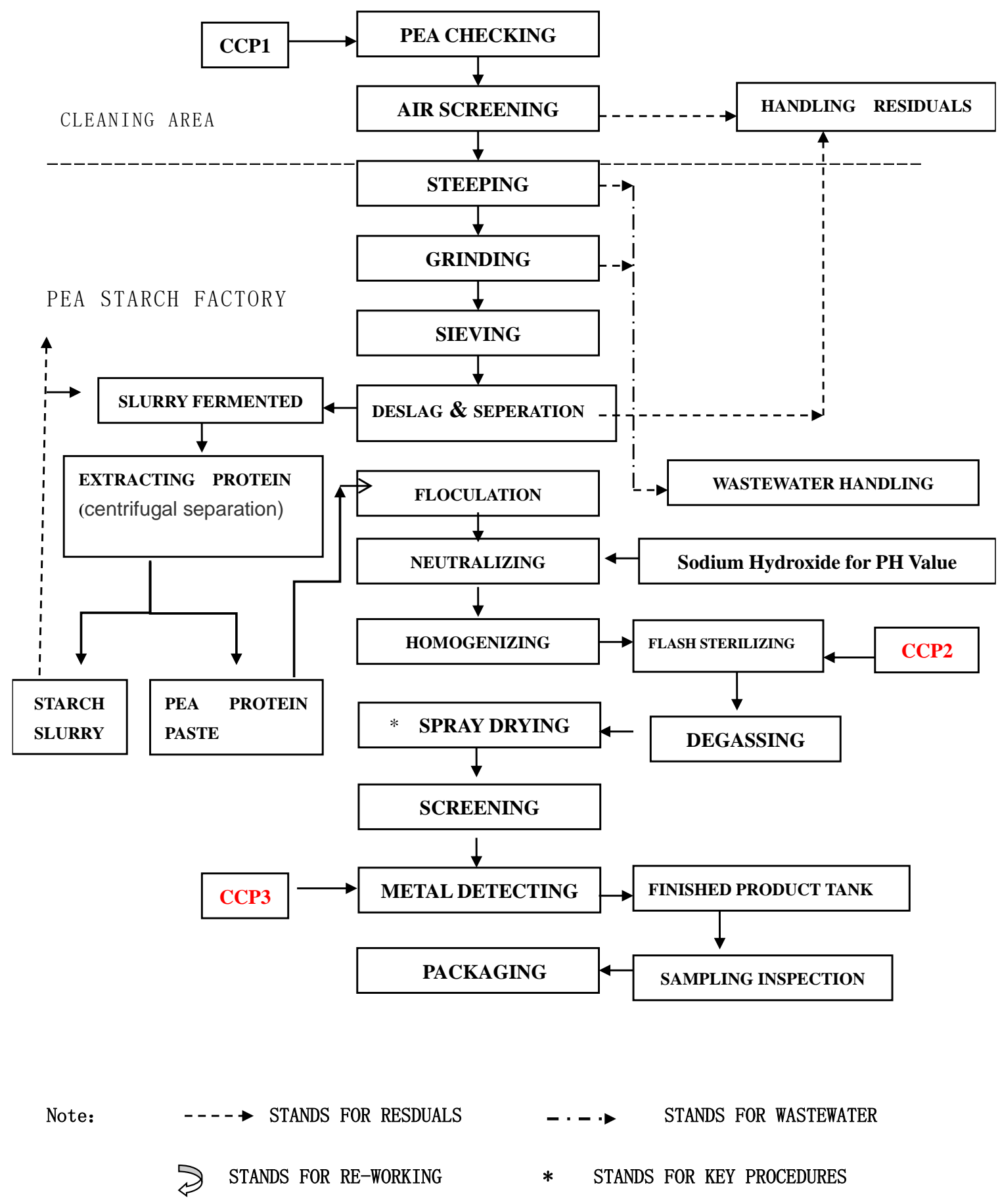

THE STEP OF 'SLURRY FERMENTED' IS NATURAL FERMENTATION WITHOUT ANY EXOGENOUS STRAINS. 
Figure S2

2

3
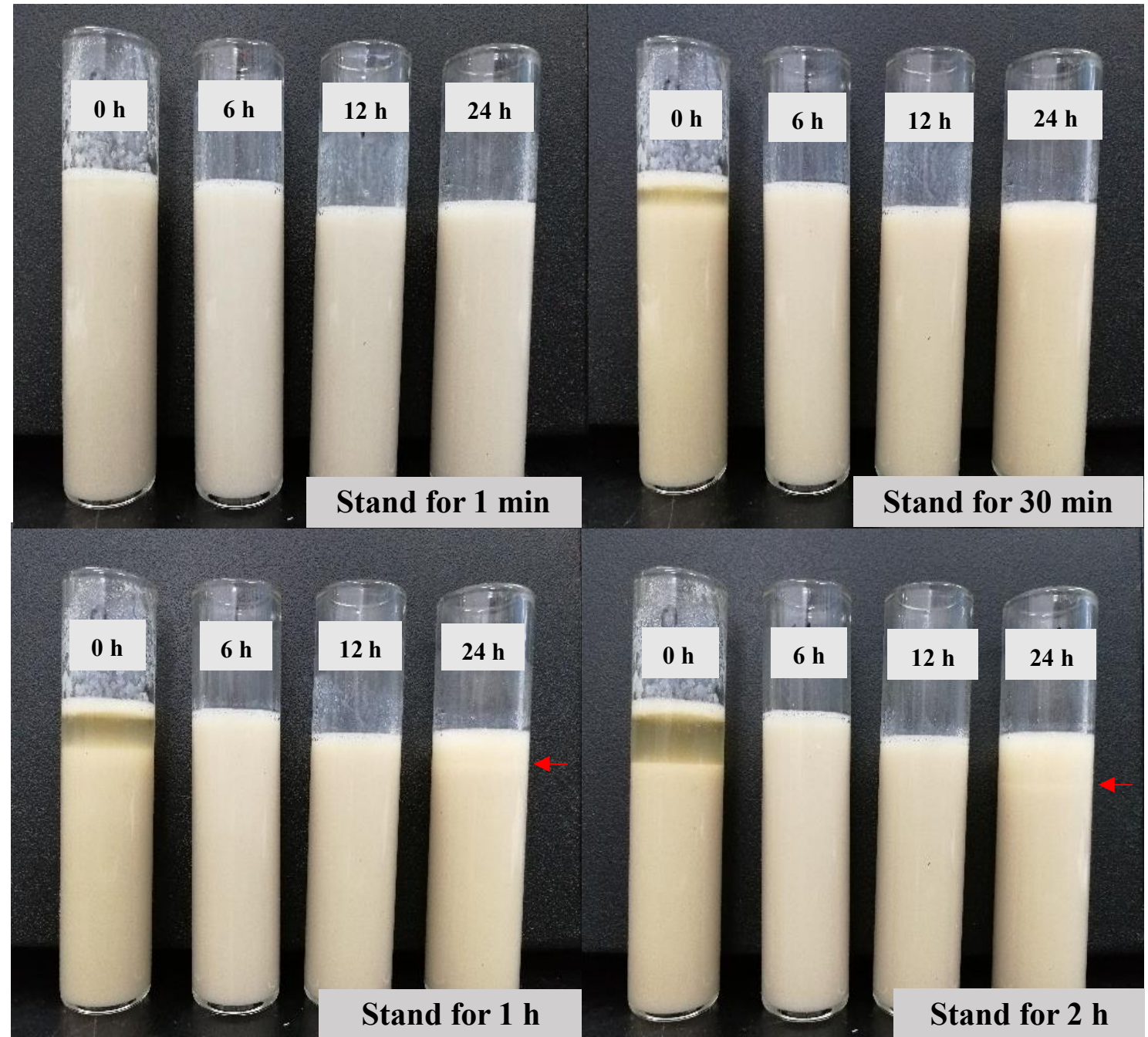
Figure S3

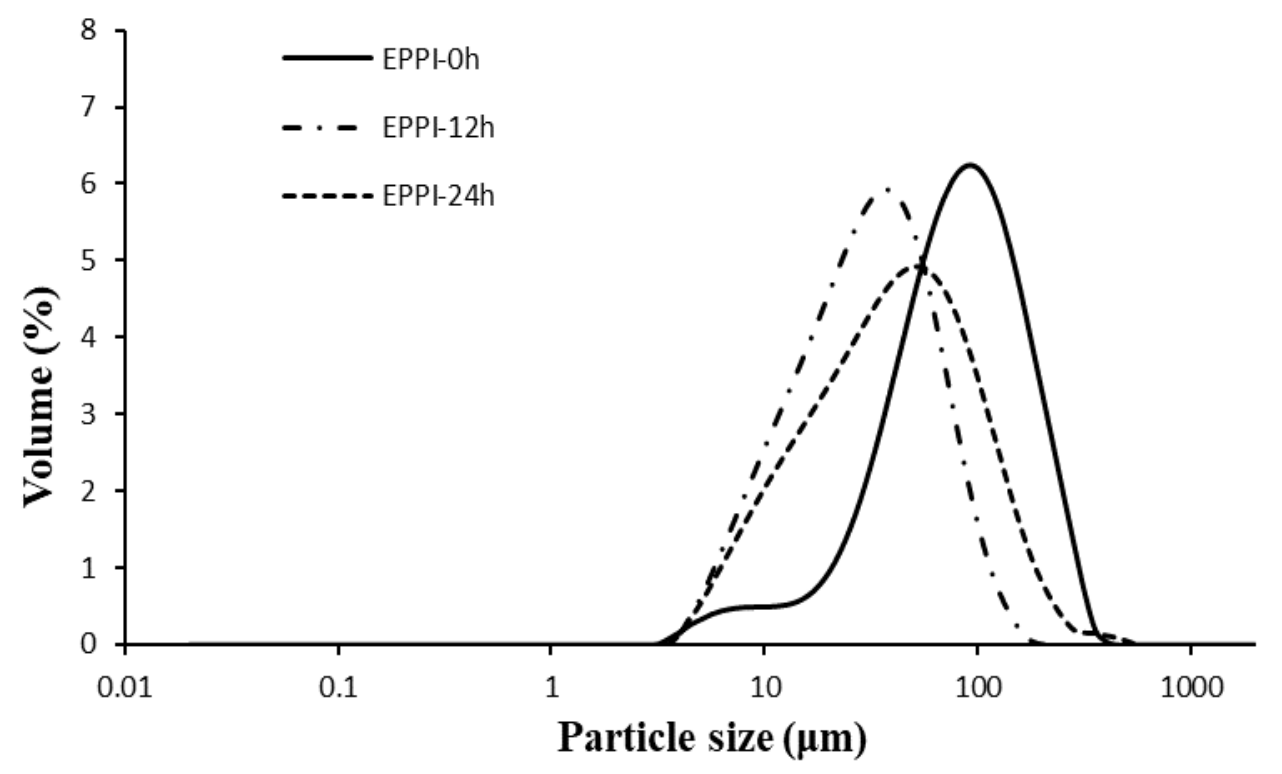

